\title{
EL EXPERIMENTO NARRATIVO EN LA OBRA TEMPRANA DE PETER WEISS
}

\author{
Luis A. Acosta
}

Peter Weiss es un autor que constituye por sí mismo un caso atípico dentro de la producción literaria alemana de los años sesenta y setenta. Ciertamente comparte con los escritores del momento los efectos de una guerra, que se extienden a varios decenios y que se notan de una manera especial en el desarrollo social, político y artístico de la Alemania del momento. Comparte con muchos de ellos las ilusiones perdidas de lo que su país pudo ser, los anhelos de que el desarrollo del mismo se encauzara adecuadamente y las dudas de que el camino iniciado haya sido el acertado.

Pero lo comparte desde la perspectiva de una vida personal, cuyos derroteros han tomado direcciones completamente distintas; una vida que necesariamente han hecho de él un autor, cuya escritura manifiesta peculiaridades muy especiales. Lo comparte desde la perspectiva de alguien que dentro de la corriente social y política de esos años, decide orientarse por el compromiso y por la toma de partido, que le lleva a dedicar gran parte de la actividad literaria al objetivo de influir en la sociedad y de colaborar en la transformación de la misma. Los cambios radicales que se producen a lo largo de su vida en la orientación de su actividad literaria, irán desde la respuesta a una solución artística vital personal de los primeros años de su producción, pasando por el compromiso político, hasta llegar a una solución que va más allá de lo personal e intimista.

Otra razón de su singularidad ha de buscarse en el hecho, profundamente significativo, del exilio, justo en una época en que Weiss no habría encontrado dificultad alguna para el regreso. Lo que por otra parte además llama la atención por el hecho de coincidir con el momento en que siente la necesidad de volver a expresarse en su lengua materna después de haber fracasado en sus intentos de hacerlo en sueco, la lengua del país que le acogió y del que se hizo más tarde ciudadano.

Conviene, no obstante, hacer ya una puntualización que supone al mismo tiempo la delimitación del contenido de este estudio. Es cierto que el desarrollo de la creación literaria de Peter Weiss pasa por varios momentos de transformaciones radicales, si es verdad lo que se acaba de decir. Sin embargo, es algo que se ha manifestado no solamente en la prosa, sino de una manera especial en el género dramático, que es lo que, sin lugar a duda, fue la 
base de la fama que disfrutó el autor durante los años sesenta y primeros setenta. Si intentamos una especie de fijación de los distintos periodos por los que ha pasado su actividad literaria, podríamos establecer, sin riesgo de equivocación, que un primero estaría formado por la producción inicial en prosa; un segundo que supone el primer cambio radical y que se manifiesta en la producción dramática, y un tercero que trae consigo la vuelta a la narrativa y que representa, a su vez, otro cambio muy profundo, en esta ocasión el último de su vida.

Este trabajo va a limitarse a analizar el punto de partida de la creación literaria del autor, que si bien no es la que más fama le ha aportado, en ella se encierra no sólo el germen de lo que va a ser las obra posterior, sino también los fundamentos necesarios para la comprensión de la misma.

Peter Weiss comienza su actividad prosística en lengua alemana a principios de los años 50 con la obra Der Schatten des Körpers des Kutschers (1952) ${ }^{1}$ - en lo sucesivo DSdKdK -, que no conseguirá publicar hasta 1959. A pesar de todo, ello, al paracer, le anima a escribir, ese mismo año, Abschied von den Eltern ${ }^{2}$ - en lo sucesivo AvdE - , publicado en 1961, Fluchtpunkt ${ }^{3}$ - en lo sucesivo FP -, en 1962, y Das Gespräch der drei Gehenden ${ }^{4}$ - en lo sucesivo $D G d d G$ - en 1963. Hasta entonces su creación literaria había consistido en una serie, más bien reducida, de pequeñas obras líricas en prosa en lengua sueca: Fran Ö till Ö (al. Von Insel zu Insel), de 1947, De Besegrade (al. Die Besiegten), de 1948, las novelas Dokument I (1949) y Duellen (al. Das Duell), de 1953 o las obras dramáticas en lengua alemana Der Turm (1948) y Die Versicherung (1952), cuyo conocimiento no había ido va más allá de círculos muy reducidos.

Son los años 30 a 35 de la vida de un autor, que había nacido en 1916 cerca de Berlín (Nowawes) de padre judío, de profesión empresaio y de madre suiza, en el seno de una familia, en que los cambios permanentes de domicilio constituyen una constante, que va desde Suecia en los primeros treinta, Inglaterra en 1934, Checoslovaquia, antes de la invasión de este país por las tropas nazis, más tarde Suiza, y desde allí, de nuevo, a Suecia donde su padre había construído una fábrica.

Interesante para una comprensión adecuada de las obras que aquí nos ocupan, resulta, sin duda, echar una ojeada a aspectos de la vida personal del autor, que nos son conocidos a partir, entre otras fuentes, de la presentación e interpretación que de ella realiza él mismo en las obras autobiográficas citadas, Abschied von den Eltern (1961) y Fluchtpunkt (1962). Resulta interesante porque se trata de alguien que es el prototipo de artista y escritor, cuya obra está enraizada de una forma directa en las circunstancias personales; un escritor, cuyas

\footnotetext{
${ }^{1}$ P. Weiss, Der Schatten des Körpers des Kutschers. Mit sieben zweifarbigen Collagen des Autors. Suhrkamp. Frankfurt am Main 1960.

2 P. Weiss, Abschied von den Eltern. Suhrkamp. Frankfurt am Main 1961.

${ }^{3}$ P. Weiss, Fluchtpunkt. Suhrkamp. Frankfurt am Main 1962.

${ }^{4}$ P. Weiss, Das Gespräch der drei Gehenden. Suhrkamp. Frankfurt am Main 1963.
} 
obras están de tal manera determinadas por esas circunstancias, que en su actividad creativa llega a transformarlas en realidad artístico-literaria. Ello por la sencilla razón de que para él escribir se constituye en un componente no sólo esencial sino también necesario de la propia vida; vida y obra se entremezclan hasta tal punto que la una no cobra sentido ni encuentra explicación sin la otra.

Weiss ha nacido en el seno de una familia típicamente burguesa, una familia representante, como dice Rischbieter, del infierno común de la familia burguesa tardía ${ }^{5}$. Esta circunstancia constituye la primera contrariedad a que tiene que enfrentarse el futuro artista, dado que dentro de ella no encuentra ni la comprensión ni la ayuda que necesita un niño. Sus padres no van más allá de ser unos extraños con quienes comparte la vida de todos los días $(A v d E$ 7). El padre es la representación genuina del patriarca inflexible que se comporta como el dueño absoluto de esposa e hijos $(A v d E$ 9). La madre es una dama distinguida marcada de manera indeleble por las costumbres y comportamientos de la burguesía ( $A v d E$ 18). El pequeño Weiss sólo encuentra en la asistenta una mínima y necesaria comprensión. Junto con los otros dos hijos que la madre aporta del matrimonio anterior, resulta una familia que podría parecer una simbolización genuina de la institución, pero que como tal símbolo se resquebraja con la muerte de los padres en el comportamiento cruel de los hermanos en el reparto del mobiliario ( $A v d E$ 13).

El primer día de escuela constituye el primer contacto de Weiss con el mundo exterior a la familia. Un día que debería haber traído consigo la experiencia positiva de la liberación del mundo familiar, sólo le proporciona el comienzo de un aislamiento paulatino que le sume en una confusión interior muy profunda ( $A v d E$ 29). La escuela en su conjunto no va más allá de una experiencia negativa donde la falta de perspectiva personal se acentúa una y otra vez. De ello resultará una persona destrozada en medio de unas circunstancias hostiles y un ser humano, cuyas esperanzas, anhelos, y sobre todo impulsos, se manifestarán de una manera que rayan la frontera del descontrol ( $A v d E$ 13-14). El resultado necesario será la introversión; sólo así se sentirá seguro de su persona, y sólo de esta manera, además, encontrará una forma de liberación y la fortaleza que va a defenderle de un mundo exterior que se le antoja enemigo. El aislamiento se convierte en una especie de exilio voluntario que dejará huellas muy profundas en el desarrollo de su personalidad; es la consecuencia del sentimiento de la decepción y del engaño del mundo exterior y la necesidad de crearse uno propio del que sólo él sea dueño y señor, con todos los riesgos y peligros que de ello van a resultar ( $A v d E$ 16) y que pronto van a aparecer.

Esto ocurre en su época de pubertad en la confrontación con la experiencia del mundo de los sueños, que percibe de forma completamente distinta a como percibe la realidad común de todos los días. Los impulsos y tendencias que capta de manera clara y contorneada en aquella esfera, sufren una gran limitación en el mundo de los sentidos. A partir de este contraste el joven Weiss se crea un mundo personal extraño. La aparición de la actividad sexual que se le ofrece de una manera espontánea en la realidad onírica, contrasta con las

\footnotetext{
${ }^{5}$ Vid. H. Rischbieter, Peter Weiss. Friedrich, Velber bei Hannover 1967.
} 
limitaciones a que está sometida en la realidad de la vida diaria. De ello es una muestra no poco significativa la idea que pretende inculcarle la madre de que el sexo es algo sucio, algo contra lo que tiene que entablar una lucha sin cuartel, ya que se trata de algo que es consecuencia de los permanentes malos pensamientos que le sobrevienen (AvdE 51). Con todo, observa que las mujeres que según este principio tiene que evitar en la vida real, son precisamente quienen le atacan en los sueños. La observación, por otro lado, de que el onanismo y la homosexualidad son frecuentes entre los compañeros, hace que su situación cobre dimensiones críticas. La satisfacción sexual que experimenta en los sueños, se convierte en insatisfacción en la experiencia de la vida real. Ciertamente la solución no está tampoco en la materialización del principio, también de la madre, de que

"... leben heißt arbeiten, arbeiten und immer wieder arbeiten." (AvdE 56).

Todo ello puede dar una explicación al hecho de que la sexualidad será un factor de importancia en la obra que constituye el objeto de este trabajo.

A medida que pasa el tiempo, el aislamiento va haciéndose cada vez mayor, de forma que se convierte en el terreno abonado para comenzar a escribir, a pintar y a escuchar música con tal dedicación, que rechaza todo lo que no tenga que ver con estas actividades. De todas ellas, la de escribir se convierte, no tardando mucho, en el único instrumento de liberación personal. Esto ocurre a la edad de 17 ó 18 años, esto es, la época de Londres, y es la ocasión que llevará necesariamente al conflicto con su padre que no acepta de su hijo que se dedique a estos menesteres.

En los años de Checoslovaquia entra por segunda vez en contacto con el mundo exterior. Es con ocasión de la lectura del Steppenwolf (El lobo estepario) (1927) de Hermann Hesse, a quien Peter Weiss escribe una carta y del que, no pasado mucho tiempo recibe contestación. Sin embargo, la respuesta le decepciona, dado que su contenido no responde a las expectativas que se había creado. Hesse en su carta le habla del trabajo realizado pacientemente, de la dedicación concienzuda y continuda al estudio, de la necesidad de crearse una forma de vida que permita ganarse el sustento y de los peligros de una vida aislada y solitaria ( $A v d E$ 120). Los años de Praga son los años de la Escuela Superior de Arte y los años de una nueva decepción. La clase de pintura constituye un centro especial de interés; pero a fin de cuentas no le proporciona la satisfacción esperada, entre otras razones porque no acepta las reglas y métodos estrictos de acuerdo con los cuales discurren las actividades docentes y se canaliza la actividad pictórica. Su propia manera de pintar responde a un concepto enfrentado a cualquier norma y orientación, es libre y hasta caótica, lo mismo que caótica, aunque no del todo libre, es su propia vida. Por otra parte, en la ciudad de Praga tampoco encuentra un ambiete positivo entre los compañeros, ya que de entre ellos pocos son los que como él hablan alemán. Pero como además él tampoco habla checo, ello trae como resultado el rechazo consiguiente por parte de la población autóctona. A pesar de esta contrariedades, prefiere quedarse en Checoslovaquia a tener que volver a la experiencia de la vida familiar. 
Poco después comienza la segunda guerra mundial, acontecimiento que coincide con la interrupción de sus estudios de arte y con el comienzo de un trabajo en la fábrica de su padre. Pero para Weiss la guerra no constituye una cuestión de interés, como tampoco lo es el trabajo; sus preocupaciones radican en algo que no sobrepasa los límites de la esfera de lo meramente personal. Que el mundo se deshaga en pedazos no logra atraer su atención; el objetivo personal se centra en la búsqueda de un sentido y una orientación para la propia vida ( $A v d E 143 \mathrm{ss})$.

Es en este momento - es el año 1939 - cuando la persecución organizada por los nazis contra los judíos le obliga a emigrar a Suecia. Sobre el acontecimiento de la emigración política conviene, no obstante, hacer la aclaración de que, a pesar de que es un dato histórico y biográfico relevante, sobre todo si se tiene en consideración las circunstancias políticas del momento, se trata para Weiss de algo que no va más allá de una coincidencia casual con un momento y un estadio de su vida, de ni mayor ni menor relevancia que otros momentos anteriores de la misma, que había estado marcada junto con la de su familia por la emigración, con la diferencia de que, si hasta entonces había sido por razones de tipo económico y empresarial, la de ahora es una emigración obligada. En todo caso, conviene insistir en el hecho de que el sentimiento del autor, tanto en este caso específico de emigración política obligada como en los anteriores, es que se trata de algo externo a su vida y por tanto de algo que cae plenamente dentro del ámbito de lo accidental. Lo que desempeña un papel realmente importante es aquella otra emigración interna y originariamente propia y personal, es decir, la que le lleva a la separación y apartamiento del mundo que le rodea; circunstancia que también habría tenido lugar de no haberse dado la segunda guerra mundial y la persecución de los judíos. El aislamiento hace que no se sienta vinculado ni a personas ni a cosas, el vínculo se limita estrictamente a su persona, y no se siente ligado a ningún pueblo ni a ningún ideal, a ninguna ciudad ni a ningún país; sólo busca ver realizadas sus capacidades en el hecho terrible de estar desligado de todos (FP 37).

A medida, sin embargo, que avanza la guerra y se oye hablar de los horrores que se están cometiendo, parece que Weiss reacciona de alguna manera frente al mundo exterior, hasta el punto de sentirse profundamente impresionado e incapacitado para continuar su actividad artística (FP 50). Sin embargo, ello no significa en modo alguno que en él emerja una conciencia sobre la necesidad de una toma de postura ideológica. Es algo que no se producirá hasta pasados unos años. El objetivo más importante del momento sigue siendo el de la liberación personal, que ahora cobra connotaciones claramente diferenciadas. Si hasta este momento, esto es, en las épocas de niñez y pubertad, había encontrado una salida en la introversión y en el aislamiento, esa liberación se materializa durante los años de juventud en la dedicación plena y total al arte, de manera que mediante la actividad como escritor crea una segunda vida en la que cobra claridad todo lo que hasta ahora se había manifestado de una manera oscura, imprecisa e indeterminada (FP 30).

Terminada la guerra, tiene que confrontarse, - al igual que le ocurre a la mayoría de la población que ha estado implicada en ella - con los acontecimientos macabros para los que 
no encuentra explicación alguna. Cuando se trata de narrarlos, observa que la voz interior que oye y habla de los mismos, no encuentra palabras que puedan expresarlos:

"Es war ein kläglicher, sinnloser Ruf, denn es gab keine Worte mehr, es war nichts mehr zu sagen, es war keine Erklärungen, keine Mahnungen mehr, alle Werte waren vernichtet worden." (FP 135)

Y preguntándose:

"Wo war der Styx, wo war das Inferno, wo war Orpheus in seiner Unterwelt, von Flötentrillern umrieselt, wo waren die großen Visionen der Kunst, die Bildwerke, die Skulpturen, die Tempel, die Gesänge und Epen. Es war alles zerstäubt, und nie mehr konnte daran gedacht werden, nach neuen Gleichnissen, nach Haltepunkten zu suchen, vor diesen endgültigen Bildern. Dies war kein Totenreich. Dies waren Menschen, in denen das Herz noch schlug. Dies war eine Welt, in der Menschen lebten. Dies war eine Welt, die von Menschen errichtet worden war. Und dann sahen wir sie, die Wächter dieser Welt, sie trugen keine Hörner, keine Schwänze, sie trugen Uniformen, und geängstigt scharten sie sich zusammen und mußten die Toten zu den Massengräbern tragen. Zu wem gehörte ich jetzt..." (FP 136).

La guerra deja en él una huella muy profunda, hasta el punto de que le confirma la idea que ya posee de que no vale la pena crear una vinculación con nadie, que no tiene sentido pertenecer a nadie (FP 136). Sólo en el ámbito de la actividad artística puede encontrarse la única pertenencia y vínculo posibles; por lo que ahora se dedicará de una manera más decidida que nunca sea a la actividad artística que sea. Su vida se desarrolla escribiendo, trabajando en el cine y el teatro, viajando. Volver a Alemania es algo que nisiquiera se le ha pasado por la mente. Allí solamente encontraría a sus perseguidores, y éstos hacía tiempo que le habían dado ya una respuesta (FP 62 ss).

Las dificultades, sin embargo, de escribir en una lengua extranjera aprendida, son mayores de las imaginadas, de manera que se ve obligado a empezar, por así decirlo, de nuevo e intentándolo en lengua alemana. Es la única forma de encontrar el vehículo adecuado de formulación artística imprescindible, a través del cual pueda, de un lado, aportar sentido y soluciones a su situación vital personal, y de otro, dar con la orientación genérica literaria adecuada a ese objetivo. Por lo que se refiere al primer aspecto, puede afirmarse que la solución artística no será sinónimo de solución a los problemas personales; el camino para solventarlos se abrirá con el abandono de esa fortaleza casi inexpugnable en que se ha encerrado y con la proyección de su vida hacia el exterior. Habrá que esperar todavía unos años a que esta salida del exilio interior se materialice mediante la conversión al marxismo: así su vida encontrará un sentido y la actividad literaria tomará la orientación que corresponde a la nueva situación: una obra fundamentalmente dramática que sobrepasa los límites de estas reflexiones. En relación con el primero Weiss cree econcontrar con la producción en prosa de estos años una respuesta artística coherente que le permite expresar aquellos contenidos que constituyen el centro de interés.

Antes de entrar en una consideración más próxima de las obras que son el resultado de la actividad literaria de estos años, es conveniente hacer todavía alusión a las experiencias que 
el autor ha tenido con el mundo de la literatura y otras manifestaciones artísticas que van a proporcionar, sin lugar a duda, no pocas claves para una tarea posterior.

"Alle Stadien meiner Entwicklung hatten ihre Bücher", (AvdE. 61)

A pesar de que le está prohibido leer obras de la bibloteca de su padre, aprovechará toda ocasión que se le ofrezca para verlos y hojearlos. Bien es cierto que sin disponer de un criterio determinado que le oriente a la hora de decidirse por unos o rechazar otros. Weiss recordará más tarde títulos de obras que con una sola palabra habían llegado a fascinarle, como Der Idiote, Die Dämonen, Aus einem Totenhaus, Die Elixiere des Teufels, Schwarze Fahne, Inferno (AvdE 68), Die Beichte eines Tores, Gespenstersonate, Das rote Zimmer, Fräulein Julie, Tschandala, Traumspiel. Strindberg es un autor que le atrae de una manera especial y sobre su Schwarze Fahne dice: "... das war etwas Wogendes, Trauerndes, vielleicht auch etwas Ironisches, Herausforderndes. Als ich die ersten Seiten las, mit der makabren Beschreibung der Gespenster-Mahlzeit, verstand ich, daß hier eine ganze Klasse zu Grabe ging, unter den grotesken Zeremonien, die sich zur Selbstverherrlichung geschaffen hatte." (Rapporte 6 , p. 72; en lo sucesivo, RapP). Sobre Inferno comenta Weiss: "Im Inferno-Tagebuch fand ich eine absolute Wirklichkeit. Daß dieses Buch, wie überhaupt Strindbergs Werk und Leben psycho-pathologisch bewertet werden konnte, hätte ich damals gar nicht verstanden... Heute..., sind die Thesen der Literaturhiostoriker und Psychologen wieder in den Hintergrund getreten. Ich kann keine Zeichen von Schizophrenie und Paranoia bei ihm finden, und die Augenblicke, in denen er sich selbst für wahnsinnig hielt, waren Müdigkeitserscheinungen, unter dem Druck der Verständnislosigkeit und Verhöhnung seiner Zeitgenossen." (RapP 73). Y recoge una frase de Strinberg reveladora del concepto de literatura que tiene este autor, con la que muy bien puede identificarse una parte de la propia obra: "Im Traumspiel sagt er: "Das ganze Leben besteht aus Wiederholungen". Und hier spricht er auch aus, was Dichtung für ihn ist: "Nicht Wirklichkeit - mehr als Wirklichkeit. Nicht Traum - waches Träumen." (RapP 80). La lectura de Hermann Hesse es para Weiss algo así como revolver y hurgar en el propio dolor ( $A v d E$ 119). Kafka le influye de una manera decisiva. En Praga le habían regalado Der Prozeß (El prceso) (1925) y Das Schlo $\beta$ (El castillo) (1926). La lectura de El proceso le hace consciente de aquel otro proceso que estaba teniendo lugar en torno a su persona y que le mantenía prisionero... En esta obra observa que el yo aparece desprotegido y desnudo (FP 57). De Brecht conoce Dreigroschenoper (Ópera de perra gorda) (1928) y Aufstieg und Fall der Stadt Mahagonny (Ascensión y caída de la ciudad de Mahagonny) (1929).

Busca en las biografias de pintores pero especialmente de escritores descubrir las técnicas de procedimiento utilizadas en sus comienzos, que puedan servirle de orientación para la propia actividad literaria (FP 100), comprobando que en la mayoría de los casos los autores comienzan con fórmulas que dan lugar a obras que anuncian lo que van a ser en el futuro,

6 P. Weiss, Rapporte. Suhrkamp. Frankfurt am Main 1968. (La obra recoge los siguientes contenidos: "Avantgarde Film", "Der grosse Traum des Briefträgers Cheval", "Aus dem Kopenhagener Journal", "Gegen die Gesetze der Normalität", "Aus dem Pariser Journal", "Meine Ortschaft", "Vorübung zum dreiteiligen Drama divina commedia", "Gespräch über Dante" y "Laokoon oder über die Grenzen der Sprache". 
consiguiendo así una evolución lógica continuada. En cualquier caso, la manera propia de escribir no le satisface en absoluto, sus comienzos se paralizan y fracasan hasta la desesperación; todo lo que consigue le parecen falsificaciones. No desarrolla un estilo unitario; por momentos le pasa por la mente la idea de que la literatura podría confluir con el dibujo y con la danza... pero no encuentra el camino para el supuesto de una multiplicidad artística, de un arte total (FP 101). Henry Miller le abre nuevas perspectivas con su Wendekreis des Krebses. En esta obra observa

"Die Hierarchien der Kanzleien, die alles umfassenden Gesetze waren zertrümmert, und in einem fruchtbaren Chaos begann das freie Leben" (FP 165)

Algo similar encuentra en su manera de escribir:

"Ich konnte mir keine Regeln für meine Arbeit denken... Ich wollte mich nicht aufteilen in fingierte Personen und meine Angelegenheiten von Fürsprechern austragen lassen, sondern nach dem Dieb, dem Krämer, dem Gewalttäter, dem Scheinheiligen, dem Weltverbesserer, dem Gleichgültigen und tausend anderen Kostümierungen in mir selbst suchen" (FP 166)

Una vieja conocida - de nombre Fanny - le dirá sobre su manera de escribir:

"Du willst dich als ein unteilbares Ganzes sehen, willst alles in dier anerkennen, ich glaube aber, du betrügst dich" (FP 167)

una fórmula a la que él no da importancia alguna, pero que contiene el principio formal auténtico de su técnica de escribir: "esa totalidad indivisible" habrá de encontrar una manifestación concreta en cada caso.

Por lo que al contacto con otras manifestaciones artísticas se refiere, hay que hacer la observación de que Weiss estudia la música de Hindemith y Strawinski, descubre el dadaismo, los trabajos de Picabia, Duchamp, T. Tzara y M. Ernst. Claro es igualmente su interés por el cine, cuyos géneros documental y surrealista le atraen muy especialmente. De Buñuel dirá: "In seinen ersten beiden Filmen machte Bunuel die Sprache des Traums zu einer Sprache der Wirklichkeit... In seinen nächsten Film geht er ganz von der äußeren Wirklichkeit aus, und was er dort in seinem kurzen Film Terre sans pain - Land ohne Brot, 1932 - zeigt, übertrifft jede surrealistische Vision. In Las Hurdes... trifft er eine isolierte Bevölkerungsgruppe, in der er ein Symbol für die äußerste Erniedrigung der Menshcenwerte sieht. Die Bilder, die er aufnimmt, gleichen Goyas Capriccios". (RapP 27). Conoce el cine vanguardista de Meliés, Porter, Zecca, Sjöström, Feuillade, Gance, Man Ray, Oziga Vertov, Vigo etc., al igual a los teóricos del surrealismo y, claro está, el Manifest de Breton, lo mismo que las obras de Apollinaire y de Freud.

La conclusión a que puede llegarse después de todas estas reflexiones es que ni su vida ni sus convicciones, como tampoco su forma de expresión artística, han logrado una orientación que pueda considerarse satisfactoria y mucho menos definitiva. Después de varios intentos, ahora le toca el turno a la literatura que se orientará como puro experimento, al igual que hasta cierto punto experimento ha sido la propia vida. Lo que hasta este momento ha pretendido con el teatro, con la pintura o con el cine, quiere 
experimentarlo con la narrativa, de la que son manifestaciones genuinas los cuatro títulos mencionados.

Weiss escribe Der Schatten des Körpers des Kutschers en el año 1952 a partir de las anotaciones realizadas diez años antes durante un corto periodo de tiempo de trabajo en el campo. El manuscrito estuvo dando vueltas de editorial en editorial hasta que, por fin, en 1959 fue publicado por la Suhrkamp. En la obra se presenta una finca, tal vez una posada, alejada un día de la ciudad más próxima. Aparte de la familia que trabaja en el campo, han coincidido varias personas, de las que del informe de la obra se deduce que viven allí y que no hacen absolutamente nada.

El primer interrogante que uno se plantea en la consideración de esta obra, es el referido a la asignación genérica: ¿Se trata de una narración o simplemente de un informe? La realidad es que si pretendemos identificar un concepto de género que corresponda a algo tradicional, seguro que vamos a encontrarnos con dificultades. Con todo, parece posible aceptar, de entrada, que se trata de una novela corta; por expresarlo de otra forma, de una micro-novela. Pero más importante que todo ello es el hecho de que el lector no puede por menos de observar, una vez que ha leído la obra, que se trata de un trabajo literario que no responde a un plan preconcebido, que es una obra en la que no hay una acción definida y delimitada, y que, caso de que podría identificarse alguna, sería una acción que nunca llega a un final. Es una construcción literaria que sorprende a cualquier lector que está acostumbrado a leer obras en prosa. Si nos preguntásemos entonces qué es lo que de hecho se ha propuesto el autor, habría que contestar diciendo que lo que ha pretendido ha sido justamente y nada más que escribir y contar una serie de acontecimientos que han ocurrido en el corto periodo de seis días.

Resulta así una novela estructurada en once partes o estaciones, en cada una de las cuales se describe lo que el narrador ve o lo que el narrador ha visto o ha oído y que le tiene ocupado así mismo seis días: así, en la primera estación todo lo que ve y oye desde el retrete con la puerta medio abierta; en la segunda lo mismo, recostado en la cama; en la tercera las imágenes que percibe después de haber frotado los ojos con granos de sal; en la cuarta la cena del primer día con las personas que viven en la casa; en las estaciones quinta y sexta escribe algo que recuerda y que expresa en presente y en pretérico, lo que significa que no describe lo que ve; en la séptima lo que percibe sentado en el tronco de un árbol; en la octava otra vez se pone granos de sal en los ojos; en la novena una velada nocturna; en la décima lo que ha visto el día anterior, junto con llegada del cochero; el cuarto y quinto día el narrador no escribe; y la última describe, apoyado en la ventana, las sombras que se proyectan sobre el patio de las figuras del cochero y de la dueña de casa haciendo el amor en la cocina. Con ello la obra llega a su final.

Si se analiza con detenimiento el desarrollo, observamos en primer lugar, tal y como se ha dicho antes, algo que se presenta en oposición radical a la organización clásica de la novela. No hay personajes, no hay un protagonista, no aparece un héroe, y nisiquiera, como 
ocurre en autores de los que Kafka sería el ejemplo paradigmático, un antihéroe. La figura del protagonista es simplemente asumida por el narrador. Lo mismo puede afirmarse de los personajes secundarios que se limitan a una especie de figuras de personas más que de personajes, que no entran en contacto alguno con ese protagonista, y cuya presencia está condicionada solamente por el narrador todopoderoso. El protagonista ha tomado la decisión de escribir una novela en la que casualmente hay varios individuos, que sólo pueden entenderse como componentes de la misma y nada más, al igual que, por ejemplo, los objetos que adornan la habitación de la dueña de la casa. Se trata de un protagonista, el narrador, claramente diferenciado del narrador de la novela tradicional quien como absoluto dueño de la obra y situado en una posición por encima del héroe y de la fábula, escribe e inventa a discreción ${ }^{7}$. Pero el narrador de Der Schatten des Körpers des Kutschers no pretende ni inventar ni dominar; su papel se limita tan sólo a observar y a escribir lo que ha observado. A pesar de todo, tampoco es el protanonista genuino de la obra; lo es sólo en tanto en cuanto escribe la novela y en tanto en cuanto, por esta razón, se convierte en punto de referencia de los acontecimientos que son narrados.

Por ello podría muy bien aventurarse la conclusión de que el protagonista auténtico y genuino es la propia novela en tanto en cuanto está siendo escrita, cuya acción consiste en el acontecimiento mismo de ser escrita; la fábula es así mismo la propia novela. El autor ha decidido escribir, grabar o fotografiar mediante la palabra - no mediante micrófono u objetivo fotográfico - todo lo que ve y oye. Como él mismo dice, ha decidido "... also das Sehen zu einer Beschäftigung zu machen" ( $D S d K K$ 48). Ciertamente ocurre, como es el caso del segundo día de trabajo, después de la estación sexta, que el narrador no siente ganas de continuar el relato, pero sucumbe a la necesidad de que tanto la novela como la acción tienen que continuar, de manera que, aun sumido casi en la decepción, se ve obligado a proseguir, pues de lo que de hecho se trata es de continuar escribiendo. Es, en consecuencia, algo que parece novedoso en lo que a la configuración de los personajes se refiere.

¿Qué decir del tratamiento del tiempo y de las consecuencias que trae consigo para la acción de la novela? El autor observa y describe prácticamente a continuación, lo observado; y lo lleva a cabo en tiempo presente, lo que da ocasión para suponer que se trata del resultado de percepciones que han sido llevadas al papel en un principio sólo en forma de notas, que más tarde van a tomar expresión literaria definitiva. El uso del imperfecto en lugar del presente es, en cambio, el resultado de la descripción de algo que el autor ha percibido poco tiempo antes de llevarlo a la escritura y no ha sufrido la mediación de la anotación, perteneciendo, por tanto, al pasado, aunque se trate de un pasado inmediato. En cualquier caso, el tiempo de seis días que dura la acción de la novela, ha de ser entendido como un tiempo ideal y, por tanto, no se trata de un tiempo cronológico, ni de un tiempo de secuencias fijas. En muchos casos llega a dilatarse al igual que ocurre cuando una cámara de cine actúa en movimiento lento. De los muchos ejemplos que podrían aducirse, resultan

${ }^{7}$ Vid. P.K. Kurz: Metamorfosis de la novela moderna. Traduc. del alemán. Guadarrama, Madrid 1968, pág. 36. 
paradigmáticas las tomas, esto es, las descripciones de las diferentes formas de comer y de beber de los huéspedes sentados en la mesa:

"Während der Griff der Hand um den Löffel bei allen fast der gleiche ist und man sich mehr in der Art des Handhebens, bei der Haushälterin behält der Arm und die Hand eine nahezu feste Lage und es ist der Oberkörper der sich hebt und senkt, beim Hauptmann vollzieht sich die Hebelbewegung knackend im Armbogen, Schnees Hand führt den Löffel vom Handgelenk aus zwischen dem Teller und dem tief herabgeneigten Mund hin und her, die Hand des Hausknechts stößt den Löffel wie eine Kohleschaufel in den wie ein Ofenloch vor dem Teller aufgerissenen Mund, der Schneider ruckt und zuckt mit dem gewinkelten Arm wie eine aufgezogene Gliedergruppe, ich, ich merke in meinem Beobachtungen kaum wie ich esse, voneinander unterscheiden..." (DSdKK 27)

En ocasiones, en cambio, el tiempo pasa más de prisa, como ocurre en el caso en que se reproducen fragmentos interrumpidos de diferentes diálogos o monólogos. El narrador registra partes de frases, cuidando de que sean elementos constitutivos de las mismas, y la comprensión del texto no sufra detrimento alguno:

"... ich vernehme einige der Worte aus der Folge der Sätze die Schnee ausspricht, wie besonders, ausgetrocknet, durchsetzt, nur noch zwei, werde morgen versuchen, einmal tiefer, von dort aus, wieder nicht, doch noch, wenn mal einmal, es könnte sein... (DSdKdK 35)... so jetzt, jetzt endlich, doch früher, nie wieder, wirst du nie, kannst du mir das, wie soll ich dir, wie kann ich denn, wirst du auch, habe ich dir jetzt. (DSdKdK 44)

A veces ocurre también que el tiempo se interrumpe a capricho del autor, lo que da como resultado que la novela no progrese de una forma continuada. Las interrupciones de la acción para pasar de uno al capítulo siguiente, ocurren de repente y de manera inesperada. Un ejemplo ilustrativo es el paso de la primera que ha terminado con la descripción de las piedras que hay alrededor de la casa, a la segunda que empieza con la frase

"Ich befinde mich jetzt in meinem Kammer, da der Abtritt von einem anderen Gast..." (DSdKK 13).

Algo similar ocurre con el paso de la tercera a la cuarta estación. Al final de la obra observamos que durante los días cuarto y quinto el narrador no ha escrito nada. Si puede decirse que ha hecho algo, ha sido pensar en la llegada del cochero. Se trata, pues, de un tratamiento del tiempo ideal y claramente fragmentario.

En otro orden de cosas, una de las peculiaridades de esta novela, que puede tenerse por novedosa y más llamativa, es la forma específica como se describen los objetos, hasta el punto de que su presencia se hace permanente y ocupa de una manera casi continuada la actividad del narrador. Los objetos son presentados de una manera extremadamente exacta y a la vez sobria. En la descripción no se aprecia rastro alguno de sentimiento, dando como resultado la literarización de una realidad que podríamos calificar de carente de alma. La descripción de la casa parece el resultado del movimiento de una cámara de cine ${ }^{8}$ que ha

\footnotetext{
8 Cfr. O. Best, "Vermessung der Hölle oder entseelte Realität als groteske strip. Zur Erzähltechnik von Peter Weiss’ Der Schatten des Körpers des Kutschers". Akzente, 1, 1971, pág. 47.
} 
captado un mundo físico circundante, pero que lo ha expresado haciendo uso de un lenguaje literario:

"Mein nächstes Ziel war die Schwelle der Türöffnung zur Diele und dieser näherte ich mich nun während die Gegenstände in der Küche an mir vorüberglitten, rechts der Herd mit dem darübergemauerten weißgetünchten Rauchfang, ein Topf voller Kartoffeln, ein zweiter Topf voller Rüben auf dem Feuer brodelnd, neben dem Herd, das Abwaschbecken an der Wand, mit Tellern und Bechern angefüllt, und der Tisch, unterhalb des Fensters, mit Mehl bestäubt, mit ausgewalztem Teig auf einem Brett und ein paar großen gekneteten Teigklumpen, einer Holzrolle, einer Zuckerschale und einem Löffel, und zu den Längsseiten des Tisches je eine dunkle gebeizte schmale Bank, sowie je ein Schemel an den Schmalseiten des Tisches; links der riesenhafte Geschirrschrank, mit geschlossenen Türen und Schubfächern, daneben die Standuhr, aus braunem Holz, unter dem Glas der Pendel vor in der Form von Tannenzapfen ausgeführten Gewichten langsam hin und her hertickend" (DSdKK 15)

En la última de las estaciones de la obra, el narrador, en plena oscuridad, apoyado en la ventana de su habitación, mira al patio de la casa sobre el que se propaga la luz que sale de la cocina y sobre el que se proyectan las sombras que reproduce el acto amoroso que está siendo realizado allí, conviertiéndose de este modo en material de descripción literaria:

"... so sah ich deutlich über den Schatten des Fensterbrettes den Schatten der Kaffeekanne hervorragen, und seitwärts, etwa vom Platz aus an dem die Haushälterin bei den Mahlzeiten zu sitzen pflegt, beugte sich der Schatten der Haushälterin mit vorgestrecktem Arm über den Tisch und ergriff den Schatten der Kaffekanne. Nun legte sich der Schatten des Kutschers, niedrich aus der Tiefe der Küche hervortretend, und über den Schatten der Tischkante, der in gleiche Höhe mit dem Schatten des Fensterbrettes lag, hinauswachsend, neben dem Schatten der Haushälterin; der Schatten seiner Arme streckte sich in den Schatten des Arms der Haushälterin hinein..." (DSdKK 97)

Con ello se entiende que el autor no pretende intervenir en modo alguno ni en los hechos ni en la acción de los personajes. Lo contrario supondría el riesgo de que éstos cobrasen el valor que el autor en modo alguno ha pretendido otorgarles. Es la prueba evidente de que la relación del narrador con los seres humanos de la obra no es otra que la desplegada con las cosas. Es una postura que en modo alguno es ajena al escritor moderno ${ }^{9}$. La novela moderna en uno de los caminos que ha tomado no se ocupa más que de palabras y de imágenes. Cierto que en la tradicional también había imágenes; sin embargo se trataba de relaciones entre la cosa y el hombre, pero de relaciones que ya estaban establecidas; la imagen es un estado de ánimo que corresponde a la idea que el escritor se ha hecho del mundo ${ }^{10}$.

Der Schatten des Körpers des Kutschers se constituye, en conclusión, como algo nuevo dentro del ámbito del género novelesco: es una novela de extensión más bien corta, no hay en ella ni protagonistas ni personajes secundarios, la acción es la misma novela; el tiempo es tratado de una manera que no es ni continuado ni progresivo; apenas si existe un argumento y el elemento-objeto parece constituirse como elemento nuevo y fundamental.

9 Cfr. J. Bloch-Michel, La "nueva novela". Trad. del francés de G. Torrente Ballester. Guadarrama, Madrid 1967.

${ }^{10}$ Cfr. Ibid., pág. 98. 
De esta manera Peter Weiss desarrolla una forma narrativa que se caracteriza por la búsqueda de la descripción de una manera fría y seca mediante imágenes y palabras la realidad superficial del mundo: una relación pura y sobria con respecto a los objetos literarios, bien se trate de personas bien se trate de cosas.

Pero en otro orden de cosas esta obra es el resultado del esfuerzo del autor por representar literariamente un mundo específico, cuyas dimensiones tempoespaciales apenas si pueden percibirse más que desde la perspectiva existencial. Así se entiende que esa falta de relación sea suplida por una de fundamento más consistente como es la relación artística, que mediante la utilización de la lengua establece un punto de enlace entre la conciencia aislada e incluso relegada y la realidad circundante carente de un sentido.

En 1961, aunque escrita en 1959, aparece, también en la editorial Suhrkamp, Abschied von den Eltern. Se trata de una obra en la que, de entrada, se observa, sobre todo si se la compara con la anterior, que aquí se ha desplegado la narración de una serie de hechos, de unos acontecimientos que pertenecen a la vida del propio autor y que esta narración, como efectivamente ocurre, no puede ser llevada a cabo de la manera fría y superficial con que lo había hecho en el caso anterior. Al tratarse de unos hechos de los que es protagonista el propio autor, las tecnicas fabuladoras han de tomar un desarrollo en una nueva dirección; las técnicas narrativas toman nuevos derroteros.

Abschied von den Eltern encaja plenamente dentro de la concepción tradicional de la narración autobiográfica. Se ocupa de contar la parte de la vida del protagonista, que se extiende desde la niñez hasta la emigración definitiva a Suecia. Describe la historia personal de los años en los que, como hemos tenido ocasión de ver, el futuro escritor desarrolla una vida de introversión y de aislamiento como única forma de encontrar el refugio y protección que necesita. Son los años de los primeros contactos con el exterior y de las difíciles relaciones con la familia; los años de los primeros intentos de actividad artística pictórica y literaria, de los contínuos cambios de residencia como consecuencia de los negocios de su padre etc.. El tema central de esta autobiografía es la búsqueda de la propia existencia dentro de un cúmulo de circunstancias adversas.

Pero lo que más llama la atención es la técnica narrativa que el autor ha desplegado. Si se observa lo chocante que resulta el hecho de que a lo largo de las ciento cuarenta y seis páginas de que consta el conjunto narrativo, no haya ningún punto y aparte, podría a primera vista parecer que se trata de un todo entremezclado y de elementos confusos, al que se ha privado de un punto de referencia, al que se ha privado de un contexto que le sirva de soporte novelesco. Pero no es éste el caso. Abschied von den Eltern tiene una estructura. Como obra narrativa está configurada de acuerdo con una base de construcción. Esta base de construcción es el recuerdo. Este fundamento narrativo que otorga unidad al desarrollo de la fábula, contrasta con el fundamento estructural de la simultaneidad de Der Schatten des Körpers des Kutschers, en que, como se vio, se había estructurado desde desde la casi simultaneidad entre la fijación mediante anotaciones de los acontecimientos y la formulación 
literaria de los mismos. En Abschied von den Eltern el procedimiento inicial se ha transformado, dado que las primeras anotaciones datan del año 1948, esto es, el tiempo de partida de la narración en que tiene lugar la muerte del padre del protagonista-narrador, mientras que los últimos acontecimientos narrados son del año 1939. Esto quiere decir que todos ellos han tenido lugar en el pasado relativamente lejano de la niñez y la juventud. La unidad temporal de estas dos etapas de la vida proporciona a la narración la dirección que hace que ésta se desarrolle en protensión, esto es, hacia adelante, sobre la base retencional que proporciona el recuerdo en cuanto ordenador y organizador de los acontecimientos.

Con la muerte del padre se inicia la disolución de la familia. Con motivo del reparto de la herencia el autor se encuentra con objetos que ponen en funcionamiento la actividad de la memoria con recuerdos de la niñez:

"Die Standuhr mit dem Sonnengesicht hatte in meine frühste Träume hinein gestickt, im Spiegel des riesigen Wäscheschranks hatte ich mich bei meinen nächtlichen Streifzügen in Mondlicht erblickt, in den Querleisten des Eßzimmertischs hatte ich Höhlen und Unterstände gebaut, hinter den mürben Samtgardinen hatte ich mich vor dem Fischer im Dunkeln verkrochen, und viele der Bücher, in den breiten, hohen Regalen enthielten heimliche, verbotene Lektüre" (AvdE 12).

La presencia del recuerdo como fuerza narrativa es a veces tan insistente, que el autor comienza a narrar en tiempo presente:

"... und meine Mutter steht hinter mir und sie drückt ihren Zeigefinger tief in meinen Steiß oberhalb des Afters, und ich drücke, und sie drückt, und alles ist grün, und die Straße heißt Grünnenstraße". (AvdE 15),

de modo que el recuerdo se amplía, proporcionando la ocasión para sobre la base de la palabra Grünnenstraße, contar acontecimientos que ocurrieron en esta calle. En múltiples ocasiones ocurre que aun cuando la narración se está desarrollando en tiempo pasado, en el momento en que el recuerdo topa con un acontecimiento importante, ese tiempo se convierte en presente:

"... ich floh keuchend, ich rang nach Atem, es brannte wie Feuer in meiner Kehle und in meiner Brust, und so stehe ich am Rand der Felder, und allmählich beruhigte sich mein Atem und ich fühle mich sicher, und eine Weile bin ich frei und losgelöst von allen Bedrohungen... " (AvdE 29)

La memoria puede ser caprichosa, y no es de extrañar que en ocasiones el autor interrumpa la narración de un recuerdo para comenzar a narrar otro, sin ocuparse de volver al anterior para conluirlo. No es infrecuente que un recuerdo determinado se convierta en ocasión para crear una partícula de realidad ficticia a partir de un hecho que ha ocurrido en la realidad real, pero que él no ha vivido personalmente. Es el caso de la carta que el padre había enviado a la madre desde el frente y que encuentra en el desván de la casa, la cual le sirve de ocasión para crear una realidad de este tipo, esto es, ficticia y por tanto inventada, como es la batalla en que su padre pudo haber participado ( $A v d E 41)$.

La obra pertenece al género autobiográfico. La historia es contada por un yo narrador que no limita el elemento autobiográfico a lo estrictamente histórico y externo al yo narrador, 
sino que se extiende también a aspectos que tienen que ver con su personalidad, con el ámbito de lo íntimo y más personal. El autor presenta un periodo de su vida no de una manera objetiva y detallada, una época, cuyo final, como se acaba de mencionar, se remite a diez años atrás del momento en que se escribe. Pero ocurre que diez años más tarde el autor ha desarrollado una concepción específica del arte y de la literatura, actividades ambas a las que ha decidido dedicar su vida. Una actividad literaria, cuyos resultados, de cualidad autobiográfica, tienen más el sentido de liberación de las propias experiencias del pasado que de una presentación objetiva ${ }^{11}$. Por ello, lo que al autor le interesa, no son los momentos más importantes de las épocas de niñez y juventud. No se trata de describir toda una vida llena de múltiples acontecimientos y situaciones, sino de patentizar el proceso de desarrollo y consiguiente evolución de una vida y las circunstancias que llevan a la formación de una individualidad. Sólo así se explica que lo descritọ presente una configuración sin contornos espaciales ni temporales, hasta el punto de que en ocasiones sólo es posible por referencias posteriores e imprevistas confirmar si alguno de los hechos narrados ha tenido lugar, por ejemplo, en Londres o ha sido en Praga: 92)

"Und nun stehe ich in London, im Lagerraum des Kontors meines Vaters..." (AvdE

O

"Nach Jacques Verschwinden... und als wir übersiedelten in die böhmische Stadt" (AvdE 113-114)

Parte de la huída a Suiza, de la que no se sabe a partir de esta obra, es descrita de la siguiente manera:

"Ich entkam. Ich schickte meine Bilder zu den Eltern, packte meinen Rucksack und wanderte nach Süden, ich fand ein Dorf an einem Bergsee, und blieb dort ein halbes Jahr... " (AvdE 134)

De su llegada a Suecia escribe:

"Unfähig, aus eigener Kraft zu leben, mußte ich in das Heim der Eltern zurückzukehren. Mein Vater hatte seine Fabrik... in das neue Land überführt... " (AvdE 137-138).

El tema de la narración se reduce, pues, a una especie de biografía interna, cuya razón de ser se patentiza al final del informe sobre la misma:

"Ich war auf dem Weg, auf der Suche nach einemeigenen Leben" (AvdE 146)

En múltiples ocasiones, la narración cobra casi la misma exactitud que la de Der Schatten des Körpers des Kutschers. Es el caso, por ejemplo, de los paseos de sonámbulo, en que se describen todos los objetos con que el protagonista se encuentra en el camino, creando una realidad de rasgos de autenticidad a pesar de que se trata de una realidad soñada, si bien recordada:

11 Cfr. U. Jenny, "Abschied von den Eltern". Über Peter Weiss. Ed. de V. Canaris. Suhrkamp, Frankfurt am Main 1970, págs. 47 y ss. 
"Jede Nacht satarb ich, erwürgt, erdrückt. ... da erhob ich mich aus dem Bett... öffnete die Tür... Es war ein unendlich langer Flur, hinter mir ragte die Treppe zum Dachgeschoß empor und neben mir erstreckte sich das Geländer, unter dem der dunkle Treppenschacht zur Halle lag, vor mir, in der Nische nebem dem Schlafzimmer meiner Eltern, standen... ein Paar Korbstühle...". (AvdE 44-45)

sin que a veces pueda discernirse si se trata de hechos reales o efectivamente soñados, como ocurre con la narración del momento en que el médico le aconseja que se vaya a respirar aire fresco:

"Und so gab mir eine Uniform... und schickte mich mit marschierenden Gruppen hinaus aufs Land. Abi, der Führer,... fuhr über mein Gesicht und seine dicken roten Lippen versuchten, meinen Mund zu küssen. Ich entwand mich ihn, doch der wollüstige, ekeldurchflutete Traum ging weiter" (AvdE 51-52)

Ello hace pensar en elementos de naturaleza surrealista de la narración. Weiss conoce, como se vio, el mundo artístico de los surrealistas y en su obra dramática de título Die Versicherung, - escrita en 1952 y estrenada en 1966 - intenta hacer realidad dramática el mundo de lo reprimido, el ámbito de lo subconsciente y de los sueños. En Abschied von den Eltern Weiss vuelve una vez más al tema, describiendo el subconsciente personal, que, al igual que para los surrealistas, constituye una parte muy importante de la existencia. En este sentido, resulta muy significativa la forma como el autor se manifiesta a propósito de la película de Buñuel El perro andaluz de 1929: "Diese Bilder waren hart und kunstlos, drückten nur elementare Triebe, Wünsche, Ängste aus. Auch dieser Film war nach den Prinzipien der Traumarbeit aufgebaut. Doch der Traum war hier nicht als unwirklicher Zustand geschildert, als ein isoliertes Phänomen, sondern als selbstverständlicher Bestandteil unserer Realität. Dieser Traum war eine Wirklichkeit, in der jedes Ereignis geladen mit Bedeutung ist. So wie Eisensteins Potemkin die äußere Lebenssituation analysierte und entschleierte, so schneidet Bunuel in seinen surrealistischen Werken in die Eingeweide der bürgerlichen Gesellschaftsordnung hinein, er operiert mit den schärfsten Messern, er zeigt den gekutschen modernen Menschen, mit seinen gelähmten Trieben, seinen verzerrten, verbogenen Impulsen, seinen unbefriedigten Sehnsüchten. Er arbeitet mit der surrealistischen Technik des "psychischen Automatismus". Wie in der Psychonalyse wird das Verdrängte ans Licht befördert, all das Amoralische, Barbarische, was gefährlich ist für unsere Anpassung. Zusammen mit dem Maler Salvador Dali samelte Bunuel den Stoff, in dem nichts von der Vernunft kontrolliert war, in dem die Konventionen des bewußten Denkens ausgeschaltet waren und nur die verborgenen Kräfte zur Sprache kommen sollten". ${ }^{12}$

Estas escenas no expresan nada más que impulsos, deseos y temores elementales en tanto en cuanto que son un componente lógico de nuestra realidad. Este sueño era una realidad en la que cada acontecimiento está cargado de significado. La realidad literaria resultante es el mundo del recuerdo confundido con el mundo de los sueños:

12 P. Weiss, "Avantgarde Film". Rapporte. Suhrkamp, Frankfurt am Main 1966, págs. 20-21. 
"Doch es schien unmöglich, diese zurückweichenden Gestalten, mit ihrem dunkel kichernden Stimmen, je zu berühren. Unerreichbar sah ich die Helligkeiten der Kleider in der Tiefe der umlaubten Straßen verschwimmen, benommen vom schweren Blütenduft hörte ich weiche Schritte neben mir, hörte das Flüstern einer zärtlichen Stimme an meinem Ohr, und immer tiefer halluzinierte ich mich in die Nacht hinein, bis ein Traumwesen neben mir entstand... " (AvdE 53-54).

Lo reprimido en la realidad cobra en el sueño forma de hermafroditismo:

"Abends, allein in meinem Zimmer, umgab ein wildes Meer die Insel auf der ich mit meiner Gefährtin lebte... Die Geliebte war Teil von mir, sie war das weibliche in mir, jede ihrer Regungen kannte ich, jede meiner Regungen beantwortete sie." (AvdE 54)

Naturalmente estos elementos no permiten llegar a la conclusión de que se trate de una obra a la que se puede otorgar el atributo de surrealista. Es simplemente la muestra de una forma de escribir característica de esta época, que A. Hauser ha plasmado en las palabras siguientes: "El acento se pone siempre en la falta de interrupción del movimiento, en la "continuidad heterogénea", en la pintura caleidoscópica de un mundo desintegrado. El concepto bergsoniano del tiempo sufre una nueva interpretación, una intensificación y desviación. El acento se pone ahora sobre la simultaneidad de los contenidos de conciencia, la inmanencia del pasado en el presente, el constante fluir juntos los diferentes peridos de tiempo, la fluidez amorfa de la experiencia interna, la infinitud de la corriente temporal en la cual es trasportada el alma, la relatividad de espacio y tiempo, es decir, la imposibilidad de diferenciar y definir los medios en que el sujeto se mueve en que cabe hasta el mundo de los sueños". ${ }^{13}$ Con todo, la unidad de la narración queda preservada. El recuerdo como fundamento que sintetiza la búsqueda permanente de la propia individualidad, el punto de apoyo de todo el contenido, se mantiene hasta el final.

Como en Der Schatten des Körpers des Kutschers la descripción sigue siendo la técnica de presentación literaria que domina el desarrollo del relato. La realidad descripta - la reàlidad del recuerdo - es igualmente fragmentaria; es la interna del yo histórico que se pretende actualizar mediante la utilización, una vez más, de una lengua exacta, objetiva y sobria que libere, - a excepción de la descripción de la muerte de la hermana - de contenidos sentimentales. Una lengua utilizada en ocasiones desde la consideración de una realidad autónoma, independiente de los objetos o de los hechos a que hace referencia. La lengua configurada en palabras hace que sean éstas las que se convierten en el elemento que da plenitud al texto:

"Aus der Reihe der Umstehenden trat ein Mädchen hervor, in Margits Alter, reichte meiner Mutter die Hand, knixte vor ihr, trat in den Hintergrund zurück, worauf ein zweites Mädchen vortrat, meiner Mutter die Hand reichte, vor ihr knixte, und wieder in den Hintergrund zurücktrat, worauf ein drittes Mädchen vortrat, meiner Mutter die Hand reichte, vor ihr knixte, zurücktrat, worauf ein viertes Mädchen vortrat, meiner Mutter die Hand reichte, vor ihr knixte, zurïcktrat, worauf ein fünftes und sechstes Mädchen, und noch mehr, und noch mehr Mädchen, hervortraten, ihre Hände meiner Mutter reichten, vor ihr knixten und zurücktraten, bis alle Mädchen aus Margits Klasse

13 A. Hauser, Historia social de la literatura y el arte III. Guadarrama, Madrid 1969, pág. 288. 
vorgetreten, ihre Hände meiner Mutter gereicht, und vor ihr geknixt hatten, und wieder zurückgetreten waren." (AvdE 80-81).

Ciertamente la lengua de este texto expresa un contenido; pero como consecuencia de las múltiples repeticiones de una misma acción, se consigue que la la realidad lingüística se convierta en el obejto y, por tanto, en tema de la descripción y centro de la acción. La estructura gramatical se repite una y otra vez mediante la utilización de las mismas palabras en cada una de las frases, hasta que progresivamente y sobre todo al final, el autor elimina partes completas de la frase, preserveando, en todo caso, el mismo contenido, lo que produce la impresión de que la lengua se hubiese puesto en movimiento. En ocasiones, las palabras llegan a ser utilizadas de modo que llegan hasta a perder su significado normal proposicional, logrando otro que sólo puede entenderse desde la cualidad ilocutiva propiamente literaria:

"Die Waren lagen aufgehäuft in Tropfsteinhöhlen. Zwischen körnigen Steinen, Dornen und zerfressenen Gebeinen lagen Töpfe und Knöpfe, Hosen und Dosen, Kästen und Westen, Tücher und Bücher, Flaschen und Taschen, Röcke und Stöcke, Haken und Laken, Spangen und Zangen, Kannen und Wannen." (AvdE 100-101) Enge untern Kragen, Würgen im Magen. Zurück durch das Gewühl. Leiber und Kleider, Reifen und Pfeifen, Räder und Leder, Hufe und Rufe, Nähte und Drähte, Schläuche und Bäuche, Zigaretten und Manschetten, Schokolade und Pomade." (AvdE 102) "In dem heißen, gläsernen Terrarium pries ich den Überfluß des Warenhauses, umgab mich mit Schirmen und Birnen, Stäben und Fäden, Scheren und Gewehren, Kämmen und Schwämmen, Bürsten und Würsten, Nägeln und Kegeln, Pfeifen und Seifen, Hüten und Tüten, Beilen und Pfeilen, und nahm selbst die Gestalt einer verzückt sich darbietenden Puppe an." (AvdE 103)

Obviamente nadie decora de ese modo una ventana. Cuando el autor habla de momentos importantes de su vida, la lengua se hace insistente y penetrante, lo que se consigue haciendo comenzar todas las frases con el pronombre personal de primera persona:

"Ich wußte, wie unverständlich ihr meine Bilder waren. ... Ich stand neben ihr und sah zu, wie sie mein Bild betrachtete. Ich zeigte ihr ein Bild meiner selbst. Ich wollte, daß sie lange vor diesem Bild stehen solle. Ich wollte, daß sie mich in diesem Bild erkennen solle. ... Ich wußte, daß ich nur eine kurze Frist hatte. Ich wußte, daß ich nicht mehr lange auf Gnaden hier leben konnte. Ich lebte wie ein gekuschter Hund. Ich fraß die Brocken, die man mir hinwarf. Ich verkroch mich. Ich wartete auf den Augenblick eines Ultimatums." (AvdE 103-104)

En ocasiones la lengua se estira y dilata mediante la utilización hasta el exceso y abuso de preposiciones:

"Wir hängten meine Bilder auf in einem Raum über einer Garage in einem Hof in einer versteckten Seitengasse in der riesigen Stadt in dem fremden Land in der unendlichen Welt." (AvdE 112)

De este modo, el autor continúa sirviéndose de unos usos de la lengua que había iniciado en Der Schatten des Körpers des Kutschers, con los que el efecto que se consigue no es otro que el de una realidad estética que en poco tiene que ver con la realidad estética extraliteraria. 
Un año después de la publicacion de Abschied von den Eltern, Weiss escribe Fluchtpunkt (1962), novela así mismo autobiográfica, una obra que presenta una autobiografía interna. Por lo que al contenido se refiere, puede considerarse una continuación de la anterior; se trata en este caso de la época de juventud del autor. Desde una perspectiva de contraste se observa que mientras en aquella se describía unas primeras épocas de una vida caracterizadas por la búsqueda permanente de la individuación, es decir, era el proceso de esa búsqueda la que daba unitariedad estructural a la obra, en este caso se ha producido un cambio fundamental. No se trata ya más de una búsqueda; en esta ocasión todo es una permanente huída, todo es ruptura contra las limitaciones y ataduras a que ha estado relegado durante toda su vida anterior. El experimento literario sobre el contenido de la niñez y la pubertad como momentos de búsqueda se configura de una forma diferente al experimento de escritura que literariza la ruptura con todo. Ahí radica la explicación de una nueva forma y una nueva estructura.

Con la llegada a Suecia Peter Weiss rompe con la familia, con las amistades, con las relaciones sociales. Ni siquiera en la guerra - como se vio - encuentra un significado, dado que, es de la opinión de que, tanto si le hubiese tocado del lado de los perseguidores como si le hubiese tocado del lado de los perseguidos, hubiese sido algo que habría escapado a cualquier tipo de decisión de la libre voluntad. El protagonista de Fluchtpunkt cree haber encontrado precisamente en la huída la experiencia de la libertad absoluta:

"Dies war der Augenblick der Sprengung, der Augenblick, in dem ich hinausgeschleudert worden war in die absolute Freiheit, der Augenblick, in dem ich lossgerissen worden war von jeder Verankerung, jeder Zugehörigkeit, losgelöst von allen Nationen, Rassen und menschlichen Bindungen, der Augenblick, den ich mir gewünscht hatte, der Augenblick, in dem die Welt offen vor mir lag. Jetzt konnte ich zeigen, wer ich war, was das für ein Ich war, das ich durch die Jahre der Flucht getragen hatte... Doch die Freiheit war so groß, daß ich alle Maßstäbe verlor. Ich hatte die Freiheit nicht gewonnen, ich war verurteilt zu dieser Freiheit, es war nur noch eine einzige Wahrnehmung da, die Wahrnehmung des Urübels, des Ausgesetztseins, der Verlassenheit." (FP 194-195).

Ahora bien, la consecución de la libertad personal lleva automáticamente a la búsqueda de la forma adecuada de libertad artística; una nueva forma de vida implica una nueva forma de conformación literaria. El autor decide contar los más acontecimientos posibles. Da la impresión que se trata más bien de un diario dentro del cual se registra todo que de una obra narrativa conformada de acuerdo con una estructura específica. El punto de partida es la llegada a Estocolmo; el final de la novela coincide con la llegada a la ciudad de París sólo y liberado de toda relación. Entre estos dos puntos en el tiempo se presentan muchos acontecimientos: encuentros con amigos, todos ellos emigrantes, dedicación a la pintura y exposiciones, paseos por la ciudad, recuerdos de la niñez, imaginaciones de acontecimientos de guerra, relaciones amorosas, lecturas, trabajo en el campo, reflexiones sobre una forma posible de escribir definitiva y una determinación ideológica, descripción de un entierro. El narrador escribe todo lo que le viene a la memoria. 
Prácticamente la totalidad de la novela está escrita mediante la técnica narrativa del monólogo permanente. De nuevo emergen medios de expresión que ya había utilizado en obras anteriores; la lengua y la palabra cobran realidad propia independientemente de la realidad que representan; los objetos y los hechos son descritos de forma repetitiva; el narrador observa y trascribe la realidad; describe en términos surrealistas los recuerdos y los sueños (FP 30, 31, 32, 33).

Por otra parte no hay continuidad narrativa; se interumpe el desarrollo de la acción para introducir una nueva; se quiebra la continuidad del tiempo y la sucesión espacial. Todo ello hace que la unidad de la obra haya de ser encontrada en la todalidad simbólica que configura. La multiplicidad variada de todos los hechos y acontecimientos narrados cobran razón de ser en tanto en cuanto se refieren a la cuestión fundamental que abarca toda la obra: la huída de toda realidad que invade la conciencia personal. Desde una perspectiva intertextual encuentra todo ello explicación en las palabras de Hauser, referidas a una tendencia generalizada en la escritura moderna: "Como consecuencia de la discontinuidad del tiempo, el desarrollo retrospectivo de la trama se convina con el desarrollo progresivo en completa libertad, sin ninguna clase de vínculo cronológico, y a través de los repetidos giros y vueltas en la continuidad del tiempo, la movilidad, que es la verdadera esencia de la experiencia cinematográfica, es llevada hasta sus límites extremos"14. Lo que por su parte encuentra también una explicación a partir de las experiencias del propio autor como realizador de cine y conocedor en consecuencia de las técnicas del mismo. La multiplicidad, en definitiva, del contenido encuentra su unidad estructural narrativa en relación con una idea central doble: la búsqueda de una propia individuación y el intento de práctica de un arte total con elementos de de procedencia artística múltiple, en que puedan expresarse todas las experiencias vitales. De este modo el experimento literario cobra una vez más carta de naturaleza a la vez que explicación.

Das Gespräch der drei Gehenden, de 1963, es la última obra en prosa de la época inicial; es, por otra parte, también la de más breve extensión. En la primera página de la misma nos informa el narrador ya de entrada de que se trata realmente:

"Es waren Männer, die nur gingen, gingen, gingen. Sie waren groß, sie waren bärtig, sie trugen Ledermützen und lange Regenmäntel, sie nannten sich Abel, Babel und Cabel, und während sie gingen sprachen sie miteinander... Wenn einer sprach schwiegen die beiden andern und hörten zu oder sahen sich um und hörten auf anderes, und wenn der eine zuende gesprochen hatte, sprach der zweite, und dann der dritte, und die beiden andern hörten zu oder dachten an anderes." (DGddG 7)

Estas frases iniciales permiten resumir a la perfección toda la acción de la obra. Cada caminante cuenta una historia hasta un total de treinta, hasta el punto de que no se sabe cuál de los personajes habla en cada momento. Cada una de las historias resumen acontecimientos que han vivido algunos de ellos en el pasado. Sin embargo se trata de

14 A. Hauser, Op. cit., pág. 292. 
acontecimientos que ha vivido el propio autor, a él están referidos como narrador y él es, en último término quien habla cada vez. De este modo la obra admite el matiz autobiográfico que caracteriza toda la obra anterior del autor.

A diferencia de las obras anteriores, en Das Gespräch der drei Gehenden el autor se ve obligado a tener que renunciar a la libertad que se había entonces tomado de prescindir del mundo en que se encontraba inmerso, hasta el punto de que podría interpretarse como una consecuencia del hecho de que ya no se toma el mundo tan en serio como lo había hecho hasta ahora. Peter Weiss, triple caminante, resume sus experiencias personales, parece reconocer la falta de posibilidad de progresión de las formas de expresión literaria utilizadas con anterioridad, optando ahora por la postura de enfrentarse a las experiencias personales riéndose de ellas. Es la razón por la que la realidad presentada ha dejado de ser una realidad plana y desnuda para convertirse en un mundo de caracteres cómicos e incluso hasta grotescos: el hijo busca al padre en un mar de oficinas y despachos sin lograr encontrale; las relaciones con la esposa, con quien habla de los temas más diversos, no sirven para nada. Tragicómica y grotesca es la narración de la muerte de la madre: muere después de haber dado a luz y haberse tomado una buena taza de café. Es, por otra parte, una forma de crítica política a ministros y presidentes, a la burocracia, al ejército y al nacionalsocialismo.

Con todo, la unidad de composición de la obra parece no muy consistente. Podría deducirse de la relación de la última frase de la obra con el comienzo de la misma a que se ha hecho referencia:

"Und ich kroch den Weg hinunter und lief atemlos den Uferpfad, hier, wo jetzt Straßen erbaut sind, Brücken und Kaibefestigung, hier, wo wir jetzt gehen, wo wir gehen gehen gehen" (DGddG 123)

Desde una perspectiva narrativa y estructural supone una vuelta a la fórmula desarrollada en Der Schatten des Körpers des Kutschers. Ambas obras son breves. Los acontecimientos no son narrados de manera directa, sino desde la perspectiva del narradopr intercalado que determina la presentación literaria. La ausencia de comunicación de los sentimientos del autor es casi total, lo que se manifiesta en el desarrollo de un estilo sobrio y directo.

En ella comienza a configurarse la transformación que experimentará su producción de los años venideros. No obstante, seguirá siendo un trabajo experimental y una muestra más de autobiografismo al que se han añadido elementos grotescos y tragicómicos. En su conjunto, sin embargo, supone una vuelta o tal vez mejor una continuación y el lugar de coincidencia de los experimentados realizados hasta ahora.

A manera de conclusión podría establecerse que la obra narrativa de la primera época de la actividad literaria de Peter Weiss resulta más fácil de entender, si se la considera a partir de y en relación con su vida personal. Y ello por la sencilla razón de que tanto ésta como su dedicación al arte, siguen caminos paralelos. Para el autor la vida sólo encuentra sentido en el arte, al tiempo que la forma de manifestación más adecuada del arte consiste en la 
reproducción de la vida. Es de tal manera así, que el resultado artístico final está en relación directa con las premisas que ha podido proporcionarle la vida.

Después de una lucha permanente consigo mismo a la búsqueda de un modelo de existencia que le satisfaga, Weiss llega a la conclusión de que la vida auténtica tiene que liberarse de todo tipo de ataduras y limitaciones sea cual sea su procedencia y pasar por alto toda norma y todo precepto. Una vida de esta índole sólo encuentra fundamentación en el arte, dado que es el ámbito de la existencia en el que la conciencia individual puede sentirse plenamente libre. Pero la vida es una realidad que es previa al arte, de manera que en esta dualidad el arte está, por esa razón, sometido a la vida. En consecuencia, de la misma manera que la vida consigue su sentido genuino mediante la liberación de todo tipo de ataduras, así mismo el arte consigue su forma adecuada de expresión mediante la liberación de las normas.

A una vida liberada de las normas se le puede forzar la experimentación. Aquí radica precisamente la explicación última de la prosa de Peter Weiss: Consiste, al igual que puede ocurrir con la vida, en una experimentación permanente con las formas, capaz de reproducir las experiencias de la vida del escritor. El resultado adecuado, tal y como se ha podido ver, será consecuencia de la idea de que el arte no tiene limitaciones ni fronteras. La técnica de escribir sólo puede ser experimental. 